\title{
Percepções de Gestores Sobre as Ações de Educação Alimentar e Nutricional na Escola
}

\author{
Taís Fátima Soder, ${ }^{1}$ Fábia Benetti, ${ }^{2}$ Rúbia Garcia Deon, ${ }^{2}$ \\ Dionara Simoni Hermes Volkweis, ${ }^{2}$ Cenio Back Weyh ${ }^{3}$
}

\section{RESUMO}

A Educação Alimentar e Nutricional (EAN) representa uma das mais importantes práticas e estratégias de incentivo à incorporação de hábitos alimentares saudáveis de caráter emancipatória na vida das novas gerações. Nesta perspectiva, o estudo objetivou identificar a percepção de gestores sobre a EAN no âmbito escolar. Trata-se de uma investigação qualitativa com abordagem hermenêutica. Quanto aos fins, envolve a pesquisa descritiva exploratória, e, quanto aos meios, pesquisa de campo. Os dados foram coletados mediante entrevistas gravadas com secretários de educação e nutricionistas, responsáveis técnicos pela merenda escolar (12 entrevistados) de alguns municípios do Médio e Alto Uruguai/RS. A escolha da amostra é considerada probabilística e aleatória simples. A análise de conteúdo foi escolhida como estratégia para discussão dos dados obtidos na pesquisa de campo. Quando indagados sobre a percepção da EAN na escola, os entrevistados ressaltaram essas ações como práticas reflexivas, promotoras de saúde, formadoras de atores e da autonomia alimentar. Sobre o que poderia ser feito, destacaram a necessidade de incentivo constante, de projetos integradores, capacitação de professores sobre a temática e, ainda, a importância do trabalho de EAN no ambiente familiar. Conclui-se que a escola se apresenta como ambiente favorável para o desenvolvimento de estratégias de EAN problematizadoras, dialógicas e, por considerem a realidade local, fomentando para a necessidade de gestão e adequado planejamento destas ações.

Palavras-chave: educação alimentar e nutricional; escola; gestão; percepção.

\section{MANAGERS PERCEPTIONS ABOUT FOOD AND NUTRITIONAL EDUCATION ACTIONS AT SCHOOL}

\section{ABSTRACT}

Food and Nutrition Education (FNE) represents one of the most important practices and strategies to encourage the incorporation of healthy eating habits of an emancipatory character in the lives of new generations. In this perspective, the study aimed to identify the perception of managers about FNE in the school context. It is a qualitative investigation with a hermeneutic approach. As for the ends, it involves exploratory descriptive research and as for the means, field research. Data were collected through recorded interviews with education secretaries and nutritionists, technicians responsible for school meals (12 respondents) from some municipalities in the Middle and Upper Uruguay / RS. The choice of the sample is considered simple probabilistic and random. Content analysis was chosen as a strategy for discussing the data obtained in the field research. When asked about the perception of FNE at school, respondents highlighted these actions as reflective practices, health promoters, trainers of actors and food autonomy. Regarding what could be done, they highlighted the need for constant encouragement, integrative projects, teacher training on the subject and, also, the importance of FNE work in the family environment. It is concluded that the school presents itself as a favorable environment for the development of problematic, dialogical FNE strategies and, considering the local reality, promoting the need for management and adequate planning of these actions.

Keywords: Food and nutrition education. School. Management. Perception.

RECEBIDO EM: 20/7/2020

MODIFICAÇÕES SOLICITADAS EM: 15/9/2020

ACEITO EM: $12 / 3 / 2021$

\footnotetext{
${ }^{1}$ Autora correspondente. Universidade Regional Integrada do Alto Uruguai e das Missões - Campus de Frederico Westphalen (URI/FW). Av. Assis Brasil, 709 - Bairro Itapagé. Frederico Westphalen/RS, Brasil. CEP 98400-000. http://lattes. cnpq.br/8452578476654270. https://orcid.org/0000-0002-5743-6281.

2 Universidade Regional Integrada do Alto Uruguai e das Missões - Campus de Frederico Westphalen. Frederico Westphalen/ RS, Brasil.

${ }^{3}$ Universidade Regional Integrada do Alto Uruguai e das Missões - Campus de Santo Ângelo. Santo Ângelo/RS, Brasil.
} 


\section{INTRODUÇÃO}

A EAN vem destacando-se como uma importante estratégia de promoção da saúde. Diante disso, apresenta um papel de relevância social na medida em que proporciona uma reflexão crítica sobre as questões alimentares para o desenvolvimento de hábitos saudáveis, considerando o seu papel vital e biológico bem como os aspectos sociais e antropológicos, visando à promoção da qualidade de vida.

O Marco de Referência de EAN para Políticas Públicas, no contexto da realização do Direito Humano à Alimentação Adequada (DHAA) e da garantia da Segurança Alimentar e Nutricional (SAN), compreende tal termo como "um campo de conhecimento e de prática contínua e permanente, transdisciplinar, intersetorial e multiprofissional que visa promover a prática autônoma e voluntária de hábitos alimentares saudáveis". Ainda contempla que sua prática "deve fazer uso de abordagens e recursos educacionais problematizadores e ativos que favoreçam o diálogo junto a indivíduos e grupos populacionais", considerando, ainda, "todas as fases do curso da vida, etapas do sistema alimentar e as interações e significados que compõem o comportamento alimentar" (BRASIL, 2012a, p. 23, 2018a).

Assim, a EAN representa, atualmente, uma das mais importantes práticas de incentivo à incorporação da alimentação saudável, de maneira emancipatória e preservando a cultura e a autonomia dos indivíduos. Como consequência desta intervenção específica, o termo vem sendo abordado em muitas políticas públicas, principalmente referindo-se a estratégias de ação, como pode ser observado desde a redação do Programa Nacional de Alimentação Escolar (PNAE) até a inserção da EAN no currículo escolar (BRASIL, 2009, 2018b).

A preocupação com a EAN nas escolas vem aumentando na medida em que cresce o número de crianças e adolescentes com obesidade e comorbidades. As consequências da obesidade infantil incluem o aumento do risco de asma, diabetes mellitus tipo 2 , distúrbios ortopédicos e redução do desempenho acadêmico. Sabe-se que a obesidade infantil é influenciada pela exposição pré-natal à obesidade materna, e está associada à pobreza, insegurança alimentar e má qualidade nutricional, indicada pelo consumo excessivo de carboidrato simples, gordura de má qualidade e sódio em detrimento de alimentos ricos em fibras, vitaminas e minerais. Isto é, preferência aos alimentos industrializados em comparação com os naturais, como frutas, verduras, leguminosas, laticínios, cereais e tubérculos (DEAL et al., 2020; NASREDDINE et al., 2018). Essa transição nutricional e de perfil epidemiológico da população leva a questionamentos acerca das condições alimentares a que estão sendo expostas as crianças, fortemente incentivadas ao consumo de alimentos industrializados pela mídia e grandes indústrias (LOPES et al., 2020).

Considerando tal contexto, buscou-se identificar as percepções de gestores e nutricionistas acerca da EAN no âmbito escolar. O que poderia ser feito em termos de EAN em âmbito escolar? A partir desta compreensão foi realizada uma investigação junto aos secretários de educação e nutricionistas responsáveis técnicos pela merenda escolar de alguns municípios demarcados territorialmente pela abrangência da 20ạ Coordenadoria Regional de Educação (20a CRE/RS).

Editora Unijuí - Revista Contexto \& Saúde - ISSN 2176-7114 - v. 21, n. 43, jul./set. 2021 


\section{MATERIAIS E MÉTODOS}

$\mathrm{O}$ artigo resulta de um estudo qualitativo com uma abordagem filosófica e enfoque hermenêutico, na medida em que esta estabelece princípios e métodos de interpretação. Quanto aos fins, trata-se de pesquisa descritiva e exploratória. Quanto aos meios, envolve uma pesquisa de campo, posto que a pesquisa se realiza no ambiente de cada sujeito da pesquisa.

Para o lócus de pesquisa foram selecionados seis municípios pertencentes a 20 ${ }^{a}$ Coordenadoria Regional de Educação (CRE-RS), que compreende 28 municípios de atuação. A seleção destes ocorreu por meio de sorteio segundo a Resolução no 196/96 do Conselho Nacional de Saúde. A escolha da amostra, portanto, foi probabilística, com amostragem aleatória simples. Em relação aos sujeitos da pesquisa, foram considerados os gestores (secretários da educação) e nutricionistas (responsáveis técnicos pela merenda escolar). Para a população amostral de cada grupo de sujeitos foram considerados 2 participantes por município, considerados cerca de $20 \%$ dos indivíduos, compondo 6 municípios e 12 sujeitos. Tal número amostral foi escolhido observando alguns aspectos para o delineamento de pesquisas qualitativas: reflexão sobre o que se espera dos entrevistados, o tempo das entrevistas e a facilidade de acesso aos entrevistados.

$O$ instrumento utilizado para a coleta de dados foi a entrevista semiestruturada, isto é, direcionada por um roteiro previamente elaborado, composto, geralmente, por questões abertas e fechadas. As entrevistas foram realizadas nos meses de julho e agosto de 2016, utilizando-se um gravador. Quanto à análise dos dados, foi considerada a análise qualitativa com respectiva análise do conteúdo (SOUZA, 2019).

Conforme previsto na Resolução 466/12 do Conselho Nacional de Saúde, foram respeitados todos os procedimentos relacionados à pesquisa que envolva seres humanos. Neste sentido, o estudo foi aprovado pelo Comitê de Ética em Pesquisa sob $n^{\circ}$ do CAAE 55146816.0.0000.5352. Nesta investigação, o Termo de Consentimento Livre e Esclarecido (TCLE) foi entregue ao pesquisado em duas cópias, com a assinatura e contato do pesquisador, sendo uma das cópias devolvida a ele para comprovação do aceite da pesquisa.

Após a entrevista, os dados coletados foram transcritos pela pesquisadora e tabulados, utilizando-se, para isso, o Excel, sendo os sujeitos codificados com as seguintes siglas: S (Secretário da Educação), e N (Nutricionistas), que foram organizados em números cardinais em ordem sucessiva, respeitando o anonimato dos indivíduos pesquisados.

Reitera-se que a pesquisa não dependeu da aprovação da $20^{\text {a }}$ CRE-RS. Apenas utilizou-se sua delimitação geográfica como meio de delimitação dos municípios de abrangência da pesquisa.

\section{RESULTADOS E DISCUSSÕES}

Dos 12 entrevistados, um era do sexo masculino e 11 do feminino. A média de idade entre os profissionais foi de $38,58 \pm 12,04$ anos. Na categorização dos secretários municipais de educação, estes apresentaram média de idade de

Editora Unijuí - Revista Contexto \& Saúde - ISSN 2176-7114 - v. 21, n. 43, jul./set. 2021 
$49,17 \pm 6,46$ anos, e os nutricionistas de $28 \pm 6,10$ anos. Quanto à escolaridade, 1 tinha curso superior e 10 especialização, e, entre eles, 3 em andamento; 2 dos entrevistados apresentavam Mestrado como último nível de escolaridade. A média de atuação profissional na respectiva função foi de 40,42 \pm 19,93 meses, embora muitos dos entrevistados relatassem atuação em outras funções anteriormente.

A percepção, tratada aqui, busca resgatar as características atribuídas às ações de EAN na escola ante a visão de um sujeito dotado de experiências, conhecimentos, saberes, vivências, observações e interações com a realidade que o cerca. Com base nesta perspectiva, tais percepções representam, também, o recorte geográfico de ações de gestão que ocorrem em muitos municípios da região.

Neste sentido, investiga-se a imagem constituída pelos entrevistados sobre esse processo da EAN. Quando, portanto, indagados sobre as percepções das ações de EAN na escola, destacaram como sendo uma prática reflexiva, um conjunto de ações e resultados de ações desenvolvidas nas escolas e nas famílias.

Neste cenário, alguns participantes afirmaram a relevância da EAN no âmbito da promoção de saúde, conforme pode-se ratificar nas seguintes falas:

"É uma prática importante para a promoção e desenvolvimento de conhecimentos dos atos alimentares saudáveis desses alunos, dessas crianças e para que eles aprendam e reflitam sobre a alimentação adequada [...]" (N1).

"[...] é desde pequeno que tu tornas o hábito alimentar da criança muito meIhor para a vida inteira." (S2).

"Então eu acho que ter uma boa educação nutricional e alimentar na escola é a base da alimentação da criança para o futuro [...]" (N3).

"[...] na nossa secretaria temos a nutricionista que organiza ações para o incentivo aos hábitos saudáveis [...]" (S3).

"Percebo como importantes e necessárias. Porque as crianças precisam se alimentar de forma adequada. Elas estão na fase de crescimento! É preciso comer uma quantidade de proteína, de vitaminas, de ferro, cálcio [...]" (S5).

Pressupõe-se que a promoção da saúde mediada pela alimentação tem propósitos cada vez mais reconhecidos. A perspectiva de que o estilo de vida atual pode interferir no futuro é considerado pelos sujeitos que, ao complementarem que a formação de hábitos alimentares se dá na infância, induzem à concepção de qualidade de vida, do autocuidado, bem-estar e da própria promoção da saúde. O conhecimento sobre a ciência, sobre os alimentos, sobre o que é a representação do saudável, também é mencionado pelos participantes, fomentando para a necessidade de reflexão da temática.

Algumas percepções assumiram caráter mais técnico, isto é, da educação nutricional voltada aos aspectos nutricionais e atitude biológica de prevenção de doenças.

"A preocupação do municipio, que é preocupação nossa, é de buscar essas crianças... as doenças, obesidade, essa parte \{...\} Mas a preocupação mesmo nossa é com a família mesmo, em casa: Como que é a alimentação? Há uma alimentação adequada para essas crianças? [...]" (S1). 
"[...] E também é para prevenir muitas das doenças que têm ligação com a alimentação exagerada, sem limites e inadequada" (S5).

As marcas da transição nutricional estão explícitas: alimentação monótona e aumento considerável de doenças associadas à alimentação. Sem dúvida, a prevenção destas DCNTs, cujo emaranhado custo financeiro entope as contas governamentais, não pode ser reduzida apenas ao estreito caráter biológico, mas envolve, ainda, aspectos físicos, psicológicos e socioeconômicos. É nesta perspectiva que o comportamento alimentar tem característica fundamental: é capaz de desenvolver proteção ou risco para distúrbios alimentares, obesidade e doenças crônicas (D’AVILA; CÁS; MELLO, 2020). Desta forma, cabe incentivar, principalmente por meio da EAN, hábitos de vida saudáveis desde a infância, de modo a prevenir a obesidade e demais comorbidades (MAGALHÃES; CAVALCANTE, 2019; MARREIRO; SEMIAN, 2019). Destaca-se, ainda, como fundamental, que crianças e adolescentes evitem a dieta ou outros comportamentos conscientemente restritivos, pois estes têm sido associados ao ganho de peso e à compulsão alimentar (WILSON, 2020).

Nas entrevistas, a educação alimentar também foi reforçada como um aspecto importante a ser trabalhado, e apresenta, muitas vezes, aproximações com os princípios do Marco de Referência de EAN para Políticas Públicas, ao destacar a autonomia, $\mathrm{o}$ ato de comer e a comida.

"Penso que a EAN deve se preocupar com as representações sobre o ato de comer e a comida também. Por isso o trabalho com coletividades é eficiente, porque a alimentação é um ato social. Se preocupar, buscar e trabalhar com os conhecimentos, com as atitudes e valores da alimentação para a saúde, buscando sempre a autonomia do indivíduo" (N2).

Vale ressaltar que este processo de (re)pensar no alimento, na comida, exerce um papel central na reflexão das atitudes alimentares. A partir disso, pode-se indagar: De que forma a autonomia beneficia a cultura alimentar e escoIhas saudáveis? Como favorecer a autonomia nas ações de EAN de forma efetiva e problematizadora? De fato, a autonomia apresenta-se, aqui, como chave de ignição das escolhas alimentares condizentes com a memória cultural alimentar, experiências gustativas, disponibilidade de alimentos ou quaisquer outros fatores que possam influenciar tais escolhas.

Autonomia [...] Por que o melhor tempo para esta tarefa é sempre o dos pais? Por que perder a oportunidade de ir sublinhando aos filhos o dever e o direito que eles têm, como gente, de ir forjando sua própria autonomia? Ninguém é sujeito da autonomia de ninguém. Por outro lado, ninguém amadurece de repente, aos 25 anos. A gente vai amadurecendo todo dia, ou não. A autonomia, enquanto amadurecimento do ser para si, é processo, é vir a ser. Não ocorre em data marcada. É neste sentido que uma pedagogia da autonomia tem de estar centrada em experiências estimuladoras da decisão e da responsabilidade, vale dizer, em experiências respeitosas da liberdade (FREIRE, 1996, p. 41).

Seguindo na linha deste pensamento, estimular escolhas saudáveis vai além da comunicação e necessita de uma dialogicidade em que ambos aprendam, ensinem e reconstruam suas visões sobre a alimentação. Desta forma, a

Editora Unijuí - Revista Contexto \& Saúde - ISSN 2176-7114 - v. 21, n. 43, jul./set. 2021 
autonomia é uma característica construída e conquistada a cada dia, a cada escolha e que pode e deve ser incentivada desde a infância.

Segundo Maria Cristina Faber Boog (2013), a efetiva incorporação de hábitos alimentares saudáveis sempre envolve a educação: "educar para promover a alimentação saudável implica intervir na vida das pessoas com ética, com conhecimentos técnicos e com profunda compreensão da condição humana" (p. 53).

Ainda, segundo relato, "a EAN deve se preocupar sobre as representações do ato de comer e da comida" (N2), considerando-se que não se apresenta apenas como nutriente indispensável ao corpo e às interações metabólicas, mas também como uma atitude prazerosa, permitindo a conexão com os significados que envolvem herança cultural, tradições, memória afetiva e momentos de sociabilidade (LIMA; NETO; FARIAS, 2015).

A escola também foi referenciada como um ambiente adequado para promover a EAN. Segundo os sujeitos da pesquisa:

E a escola é um campo muito fértil, [...] é imprescindivel na realização de EAN, porque ela engloba toda uma comunidade escolar. [...] pode envolver as crianças, os adolescentes, os pais, os professores, a direção, os outros familiares. [...] A instituição é um campo muito bom para ser trabalhado porque a gente tem uma coletividade. [...] (N2).

Toda a educação, toda a ação que é feita, forma atores. Porque é feito um trabalho dentro da escola. Esse trabalho reflete dentro da casa das famílias também (N4).

Às vezes, até a mãe vem e pergunta o que colocam naquela merenda que o aluno come na escola e não come em casa. O que a gente percebe, às vezes, que o coleguinha come aquela merenda. Para ele se enquadrar no contexto da turma ele acaba comendo também a comida. [...] é também uma questão de socialização (N4).

Capacita a merendeira também para trabalhar essa parte da educação alimentar. E sempre, na verdade, nosso trabalho é o incentivo com aluno também, com o consumo dos alimentos. A gente acaba cobrando também: coloca, incentiva, faz com que a professora incentive também (N6).

A fertilidade adjetivada na comunidade escolar reproduz um ambiente adequado de aprendizagem e de troca de experiências promissoras. Esse cenário favorável se dá, em grande parte, pela coletividade de pessoas, suas interações e socializações, que interferem diretamente no comportamento alimentar, como demonstrado pelo N4, de que o aluno, condicionado pelo incentivo do colega, consumiu novos alimentos, cujo consumo não se fazia em casa. Este incentivo não se deu pela comunicação verbal, mas pela comensalidade.

A escola se faz na comunidade e como parte importante dela. Seu terreno fértil não se restringe somente ao chão, mas brota em toda a extensão, cujos sujeitos conseguem atingir. É por meio desta propagação que os atores da alimentação se fazem presentes e conscientes.

A partir das manifestações dos sujeitos da pesquisa pode-se perceber algumas das ações desenvolvidas nos municípios:

Editora Unijuí - Revista Contexto \& Saúde - ISSN 2176-7114 - v. 21, n. 43, jul./set. 2021 
Na educação infantil a gente trabalha muito com os sentidos, com o paladar, tato; por exemplo tinham algumas crianças que não estavam consumindo o abacate, que é um alimento regional e que vem da nossa agricultura familiar, e que não teve tanta aceitação. Então a gente fez um trabalhinho com eles, prático, culinário. Eles fizeram a batida de abacate, e a gente vê que tem adesão depois. Outra atividade é que em outra escola de educação infantil eles fizeram os bolinhos de legumes (N2).

A gente trabalha com o sentido do cheiro, do comer, para sentir o gosto, do cheiro dos alimentos, todos com as toquinhas, e eles ajudaram as merendeiras a fazer. Então a gente consegue trabalhar e vê a continuidade até mesmo pelas próprias merendeiras. Elas trabalham com historinhas assim: porque 0 bolo de cenoura do coelho, o brócolis é a arvorezinha (N2).

No Ensino Fundamental a gente trabalha muito com palestras, com conversas [...], grupo de apoio [...]. Eu trabalho muito com a rotulagem dos alimentos, do ensino fundamental porque é algo que está inserido na realidade deles $\{. .$. (N2).

No município existem algumas aplicações e projetos de educação nutricional e alimentação saudável dentro da escola (N5).

Dentro do projeto pedagógico da escola já tem atividades, a roda da fruta, a pirâmide dos alimentos [...] (N6).

A adequação das ações e atividades direcionadas aos grupos específicos, em que a faixa-etária torna-se um fator relevante, é necessariamente indispensável para o bom andamento e concretização dessas ações. Essa concepção comunga com a relevância da ludicidade ante o incentivo dos hábitos alimentares saudáveis por intermédio da EAN: o valor do lúdico na educação tem sido um dos principais instrumentos pedagógicos que fomentam um aprendizado de qualidade e diferenciado para a criança, a partir das técnicas que promovem o desenvolvimento das habilidades fundamentais nesse processo. Quando atrelada às técnicas lúdicas, a EAN contribui para o início de valores e atitudes relativas à alimentação saudável para a promoção da saúde e também para a prevenção de doenças (MODESTO; SILVA; FUKUI; 2020; MEDEIROS et al., 2019; RODRIGUES et al., 2020).

Segundo a neurociência, por meio do lúdico o educador pode proporcionar situações de aprendizagem prazerosas, desafiadoras, que sejam capazes de gerar um estado de vibração e euforia, favorecendo o aprendizado de forma significativa e eficaz. Tais ações lúdicas, como brincadeiras, jogos e desafios, possibilitam desenvolvimento motriz, assimilação de novos conhecimentos, fortalecimento de memórias, desenvolvimento da sociabilidade e potencial criativo (NOGARO; FINK; PITON, 2015). Isto evidencia que a aprendizagem é um processo individual e coletivo, e que se aprende mais substancialmente quando envolve emoções, sentidos e outros mecanismos cerebrais.

É nessa perspectiva que a associação de alimentos com animais, plantas, super-heróis e contos de fadas (fortemente influenciadores no imaginário infantil) e o trabalho com os órgãos do sentido, tornam as ações mais prazerosas e interessantes para as crianças. As músicas, paródias, poesias, danças, teatros e dinâmicas também se concretizam como importantes meios pedagógicos de realizar a educação alimentar, não somente com o público infantil, mas quando, adequadamente planejadas, com os adolescentes, gestantes, adultos e idosos.

Editora Unijuí - Revista Contexto \& Saúde - ISSN 2176-7114 - v. 21, n. 43, jul./set. 2021 
A rotulagem de alimentos utilizada para realização de EAN por um dos sujeitos da pesquisa foi justificada pela inserção na realidade dos alunos. Esta é a característica mais significativa para abrir o leque de interesses pelas ações. Para Freire (1996), mais do que mergulhar na esfera da realidade, as ações educativas devem, sobretudo, desafiar o educando a pensar criticamente a realidade social, política e histórica em que é presença. O autor, então, reafirma: "como uma prática estritamente humana jamais pude entender a educação como uma experiência fria, sem alma, em que os sentimentos e as emoções, desejos, os sonhos devessem ser reprimidos por uma ditadura reacionalista" (FREIRE, 1996, p. 41).

A merenda escolar igualmente foi tratada como promotora da EAN. No conteúdo conceitual de alguns dos relatos, entretanto, a questão da merenda escolar foi prevalente.

O próprio cardápio também atua como uma EAN. Eles aprendem, vendo as refeições na escola, como é. Muitas crianças recebem alimentação complementar pela primeira vez aqui (N3).

E eles são cardápios de acordo com a nossa realidade, com os gostos também, que tem a questão da aceitabilidade, e dentro dos valores nutricionais que regem as normas da nutrição (S3).

"[...] Se tens hábito saudável com uma alimentação escolar saudável, automaticamente se ele vai para casa ele cobra, de uma certa forma, dos pais também hábitos saudáveis" (N4).

"Em nossas escolas municipais a gente não tem o tal do barzinho, cantina. Nós temos só a merenda mesmo, que a escola fornece, não trazem nem de casa. Então reflete também ali na família as ações que são trabalhadas na escola e no cardápio. [...]. Até a gente vê, quando o cardápio não tem muita aceitabilidade, tentamos trocar ou fornecer aquele alimento de uma outra forma (S4).

Entende-se que a própria oferta de alimentos saudáveis na escola é considerada uma estratégia de EAN (BRASIL, 2009), pois envolve aspectos condizentes com as particularidades de cada local, como os alimentos regionais. Além disso, fomenta refeições coloridas e incentivo aos grupos alimentares, principalmente àqueles cuja transição nutricional tenta abreviar, como frutas, legumes e verduras.

Ainda, de acordo com o PNAE em seu $12^{\circ}$ artigo, destaca-se que os cardápios da alimentação escolar deverão ser elaborados [...] "com utilização de gêneros alimentícios básicos, respeitando-se as referências nutricionais, os hábitos alimentares, a cultura e a tradição alimentar da localidade, pautando-se na sustentabilidade e diversificação agrícola da região, na alimentação saudável e adequada" (BRASIL, 2009).

Para além das barreiras físicas da instituição escolar, mas ainda dentro desta, algumas atividades desenvolvidas relacionavam-se à comunidade.

[...] agora a gente tem o evento do troca-troca de sementes. Na verdade é a Terceira Amostra de Agro biodiversidade em Movimento, promovido, também, pela Emater em parceria com outras Secretarias, e eu acabei de dar a ideia de nós fazermos um Sistema Digestório Lúdico. [...] nós vamos fazer gigante. 
As crianças, agricultores, escolas também envolvidas, vão poder participar. Elas (as pessoas) entram (na estrutura do sistema digestivo) como se fosse um túnel, e têm as paradas, onde vai ser explicado por nós como que acontece a digestão dos alimentos. Vão poder vivenciar isso. A primeira parada, a boca, onde já começa a digestão dos carboidratos, do amido, daí depois do estômago, do intestino, do intestino delgado. Vai ser bem satisfatório. Deu uma trabalheira, mas vai ser bem legal! (N2).

Os caminhos para alimentação saudável adentram a agricultura familiar, sobretudo quando esta envolve a agroecologia como ferramenta de conhecimento e aplicação. Para Barbosa, Vidotto e Arruda (2015), a agroecologia é uma nova forma de se correlacionar com a natureza e com o próximo, de forma a resgatar o protagonismo do agricultor no processo produtivo, tratando, ainda, como "reforço a uma ética de respeito à vida em todas as suas expressões e ao ser humano, construindo uma sociedade ecológica, justa e solidária" (p. 2).

É neste sentido que o fomento e o crescente incentivo à agricultura familiar sustentável têm potencialidades na busca pela segurança alimentar e nutricional e na EAN aliada a princípios do bem-estar e sustentabilidade. O troca-troca de sementes crioulas proporciona a propagação da sucessão de sementes, cuja variedade e manejo poderiam ser perdidos caso não fossem compartilhadas. A erosão genética, que causa a perda de muitas espécies alimentares, já é uma preocupante realidade perante o cenário de práticas alimentares cada vez mais monótonas e padronizadas.

Por isso, é tão importante e significativo o incentivo à produção de sementes crioulas.

Ao defender e incentivar a produção de sementes crioulas na agricultura familiar, a meta é sempre resgatar e estimular os valores da cooperação e solidariedade junto as comunidades rurais, onde está toda força do resgate e produção de espécies sementeiras que estão sendo extintas. O desafio de resgatar e manter espécies de sementes ancestrais e locais só se torna viável através do manejo correto das práticas agrícolas respeitando o meio ambiente e todas as formas de vida nele envolvido, resgatando e conservando valores, conhecimentos, a cultura e a soberania alimentar dos povos (BARBOSA; VIDOTTO; ARRUDA, 2015, p. 2).

Vivenciar a digestão dos alimentos por meio do trato gastrointestinal conduz a uma experiência diversificada na busca de saberes e conhecimento. A EAN, então, pode adaptar-se aos mais diversos ensaios envolvendo a alimentação, desde o processo produtivo até o consumo e descarte de resíduos. É nesta perspectiva que a sustentabilidade tem ganhado força com vistas aos mais variados benefícios ante a biodiversidade. Partindo desta premissa, pode-se considerar a Empresa de Assistência Técnica e Extensão Rural (Emater) como uma importante promotora do desenvolvimento local das comunidades diante de tais ideais.

Cabe ressaltar, entretanto, que tal perspectiva da EAN somente terá conotação fundamental, com a adoção do "ser educador", se forem considerados os pressupostos de libertação e transformação, como afirma Freire (1983, p. 64), que "tanto pode ser usado como um recurso eficaz para 'domesticar', como pode servir a propósitos libertadores". Enquanto um compromete o conheci-

Editora Unijuí - Revista Contexto \& Saúde - ISSN 2176-7114 - v. 21, n. 43, jul./set. 2021 
mento e saberes populares com características mecânicas, em linhas horizontais promotoras de inferioridade (de quem sabe para aquele que não sabe) e invasão cultural, o outro tem a finalidade de valorização da sabedoria popular e comunhão com esta, criando possibilidades para a produção e/ou construção do ensinar e aprender de forma mútua, vertical e dinâmica (aqueles cujos saberes e conhecimentos possam ser compartilhados e evoluídos) (FREIRE, 1996, 1983). Considera-se, desta forma, a necessidade de práticas de EAN dialógicas, problematizadoras e que recriem a realidade dos sujeitos.

Os participantes da pesquisa também foram indagados sobre o que poderia ser feito em termos de EAN no âmbito escolar. As possibilidades de ações voltadas a EAN proporcionaram uma reflexão de possíveis atividades para o ambiente escolar, como a origem e produção dos alimentos, questão de sustentabilidade e cuidado ambiental e, principalmente, da promoção da alimentação saudável mediante estímulos, de forma a promover a autonomia dos sujeitos.

Sim, o incentivo é o principal, na alimentação né! O estímulo da alimentação saudável por meio de dinâmicas, oficinas, diversas formas para estimular 0 interesse pelos alimentos, conhecer os alimentos, para eles terem conhecimento, aprenderem a ter cuidado com o ambiente, para saber de onde vem os alimentos, como é a produção, (inaudível) lá do resgate da produção até quando chega na nossa mesa (N1).

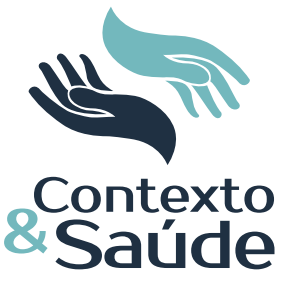

Eu acho assim, que poderia ser desenvolvidas muito mais coisas, desde mais palestras, mais atividades. Eu acho que poderia trabalhar no sentido de desenvolver mais projetos, dentro da escola, direcionado à alimentação saudável (N4).

Ter mais projetos e atividades sobre alimentação na escola e na comunidade (S5).

O foco no desenvolvimento de projetos sobre a alimentação na escola e na comunidade fortalece a perspectiva alimentar. Dentre outras ações, as registradas aqui como EAN compõem: dinâmicas, oficinas, diversas formas para estimular o interesse pelos alimentos, conhecer os alimentos, pirâmide alimentar, hortas, palestras, atividades e projetos. No conteúdo destas ações estariam ligeiramente descritos: o cuidado com o ambiente e saber a procedência dos alimentos do processo de produção até o consumo.

Assim, concebe-se que a EAN não é uma estratégia focada apenas no alimento e na nutrição. Para além do isolamento de territórios do conhecimento cada vez mais segmentados, é preciso fazer o caminho inverso. A EAN diz respeito à agricultura, como referiu a N1; "do resgate da produção" à biologia, tanto "ao cuidado do ambiente" quanto aos aspectos genéticos e celulares, à antropologia, à economia, à sociologia, entre outros. Mais do que segmentar saberes, é necessário integrá-los diante das possibilidades da EAN.

Sob um olhar historiador, um dos sujeitos entrevistados revisitou uma atividade desenvolvida na escola.

[...] Uma atividade que eu achei bem interessante que foi desenvolvida há alguns anos e que eu acho que poderia se repetir é que os professores pediram para as crianças entrevistarem seus avós, bisavós ou vizinhos mais idosos para saber da vida antiga. E nessas falas as crianças viram que a alimentação anti-

Editora Unijuí - Revista Contexto \& Saúde - ISSN 2176-7114 - v. 21, n. 43, jul./set. 2021 
gamente era bem simples, sem luxo. Mas que comiam coisas saudáveis, frutas do pé, feijão, arroz, batata. Tudo sem veneno. Tudo plantado e colhido. Não tinham geladeira, conservavam a carne na banha. E tinham muitas dificuldades, mas viviam felizes [...]. Eu acho válido retomar isso para mostrar a importância da alimentação. E os idosos se sentem valorizados também. Porque se tu chegar e falar: A comida empacotada pode fazer mal à saúde! Eles não dão bola. Assim eles vão para prática e ficam sabendo por outras bocas; acabam valorizando mais (S4).

O resgate desses saberes está intrinsecamente ligado à valorização do conhecimento e, sobretudo, das experiências dos idosos. Mais do que revisitar as lembranças, apresenta-se, ainda como função social, que aproxima gerações, para reconstruírem por meio da troca das vivências, as concepções e representações sobre a alimentação e nutrição.

Para Boog (2013), torna-se imprescindível este resgate de significados e representações que as pessoas construíram sobre a alimentação, transformando-os de forma a tornar este conteúdo pleno de sentido para a vida das pessoas e efetivo para as ações de educação em nutrição. "Por esta razão, o ponto de partida da EAN não é informação, mas a sensibilização" (BOOG, 2013, p. 58).

Tomando contornos mais largos e profundos com vistas a tais concepções, resgatar os saberes primeiros destes idosos tem fundamental importância na reflexão crítica na atualidade, fortalecendo e fomentando para a conservação histórica destas memórias. Ainda segundo relato, nesta ação as crianças puderam perceber que nem sempre se utilizava defensivos agrícolas. Surge aí a problemática em questão: em 2011 um mapeamento do Brasil sobre a utilização de agrotóxicos por município demonstrou que a Região Nordeste do Rio Grande do Sul apresentou um dos maiores percentuais do Brasil. Segundo Bombardi (2011), a maior utilização de agrotóxicos esteve associada ao agronegócio e, principalmente, ao cultivo de soja.

Outro estudo que surgiu desse preocupante cenário refere-se às regiões de saúde com maior volume de uso de agrotóxicos em litros $/ \mathrm{km}^{2} /$ ano no Rio Grande do Sul, quando a região de Frederico Westphalen/Palmeira das Missões ocupou o $3^{\circ}$ lugar do ranking das 30 regiões de saúde existentes no Estado. No que se refere à utilização de agrotóxicos críticos (princípios ativos mais prejudiciais à saúde humana), a posição subiu para a $2^{\circ}$ colocação, perdendo apenas para a região de Santa Rosa (PEREIRA, 2014). Ainda, segundo a mesma autora, as regiões de saúde mais atingidas por doenças envolvem as regiões norte e nordeste do Estado, tendo como principais cultivares a soja e o milho e, consequentemente, o uso intensivo de agrotóxicos. O processo de concentração de terras também pode ser indicativo desta realidade, reduzindo a área destinada ao plantio de gêneros alimentícios tradicionais, enfraquecendo a agricultura familiar e trazendo riscos à segurança alimentar e nutricional (PEREIRA, 2014).

Nesse panorama, as ações em EAN, principalmente no âmbito da gestão, devem agir para promover a alimentação orgânica. Para além da questão nutricional, o desafio dos nutricionistas, hoje, está na composição química dos alimentos. O progresso, proveniente da modernização da agricultura com larga utilização de agrotóxicos, é um cavalo de troia do qual aproximações causam

Editora Unijuí - Revista Contexto \& Saúde - ISSN 2176-7114 - v. 21, n. 43, jul./set. 2021 
efeitos deletérios à saúde, sem saber ainda a abrangência potencializadora de seus efeitos em âmbito biológico do ecossistema. Nesse cenário, o fortalecimento das ações de EAN deve trazer a reflexão: "Pode-se enriquecer à custa de um trabalho longo e mais penoso, que polui, degrada e encurta a vida. Mas pode-se ganhar menos, vivendo-se melhor, com menos degradação ambiental e melhor qualidade de vida. Onde está o progresso?" (ALMEIDA; NAVARRO, 2009, p. 45).

Um ponto a se considerar no relato sobre o que poderia ser desenvolvido em termos de EAN no ambiente escolar tratou da importância da higienização alimentar, principalmente com as merendeiras.

Bem, primeiramente trabalhar a higiene! A higiene a gente cobra muito. Higiene da cozinha, dos alimentos. De todo o material envolvido na alimentação escolar [...]. Assim sendo, já foi ofertado vários tipos de palestras com a Emater, dentro da própria universidade federal, do laboratório deles também [...], inclusive com alunos (S3).

Ao abordar a higienização nas cozinhas e refeitórios escolares, busca-se a promoção da alimentação segura e saudável, isto é, também com qualidade higiênico-sanitária. O trabalho da correta lavagem dos alimentos e das mãos também apresenta congruência fundamental, agregando saúde e bem-estar. Recentemente, perante os surtos virais, principalmente envolvendo a Influenza A (H1N1) e a Covid-19, a lavagem das mãos e sua assepsia e correta higienização de alimentos receberam ampla evidência (GOLDUST; ABDELMAKSOUD; NAVARI$\mathrm{NI}, 2020)$.

A realização da EAN pelos professores também foi mencionada nos relatos.

Outra questão que eu também acho interessante seria trabalhar com a formação dos próprios professores para trabalhar com EAN [...] é interessante o trabalho de EAN ser feito pelos próprios professores, porque eles podem dar continuidade ao trabalho que nós damos início. Então eu acho que é bem interessante! Principalmente os professores de educação infantil. Eu já pensei em fazer um trabalho com eles; eu pretendo fazer muito em breve a formação de professores da educação infantil para trabalhar com atividades de EAN (N2).

Pensamos, nós aqui do município, capacitar os professores para falar sobre isso; porque, querendo ou não, quem trabalha diretamente com os alunos são os professores. Eles são a referência dos alunos (N3).

o professor trabalha a parte do educar para a alimentação também (S3).

Nessa ótica, observa-se que a formação dos professores para trabalhar a EAN apresentou-se relevante nos relatos, uma vez que já trabalham o incentivo aos hábitos alimentares saudáveis e a promoção da saúde. É possível perceber que o professor está inserido na perspectiva escolar como profissional mais próximo da realidade do aluno. Além do mais, em razão de todos os aspectos didáticos e pedagógicos envolvidos na formação deste profissional, facilita o diálogo e interação de professores e alunos, inclusive na EAN, principalmente agora que essa temática está integrada no currículo escolar. Neste sentido, o profissional nutricionista apresenta-se como fundamental para a capacitação destes professores, desde a gestão das ações de EAN até a sua prática.

Editora Unijuí - Revista Contexto \& Saúde - ISSN 2176-7114 - v. 21, n. 43, jul./set. 2021 
As atividades de extensão para as famílias também foram relatadas como fundamentais.

Acredito que a EAN deveria ser trabalhada com mais ênfase em todas as fases da vida e também com os pais dentro do ambiente escolar, para ter uma continuação. Tudo que é feito na escola, continuar com os pais para ter um andamento, pois algumas questões devem ser reforçadas no âmbito familiar, para que haja a criação de hábitos e práticas alimentares saudáveis (N5).

Que eu acho que lá na fontezinha que as coisas acontecem, e que podem mudar. E eu acho essencial quando falam da família; não adianta a escola dizer uma coisa e a família fazer outra! Tem que trabalhar o todo! (S5).

O guia alimentar para a população brasileira (BRASIL, 2014a) enfatiza o ambiente familiar como prioritário na formação dos hábitos alimentares saudáveis. Aproximando-se dos descritos no Marco de Referência de EAN (BRASIL, 2012), o guia destaca que é preciso promover para a instituição familiar ações de EAN com compartilhamento de responsabilidades: "Em casa, ainda melhor do que apenas comer em companhia, é compartilhar parte ou todas as atividades que precedem e sucedem o consumo das refeições, incluindo o planejamento do que se irá comer, a aquisição dos alimentos, a preparação das refeições" e ainda não esquecendo a higienização e "as atividades de limpeza necessárias para que as próximas refeições possam ser preparadas, servidas e apreciadas" (BRASIL, 2014a, p. 97).

A presença de nutricionista trabalhando no PNAE também foi reforçada, por secretários da Educação, como sendo fundamental para ações envolvendo alimentação.

Então a gente fazia uma educação alimentar na medida do possivel. Mas no momento que ela entrou mudou totalmente. Até a questão de cardápios, de nutrição. Eu acho, assim, que foi uma mudança muito grande pra educação alimentar. Ela (nutricionista) está fazendo toda aquela questão de medida de peso, avaliação deles. Hoje eu não vejo mais a Educação sem uma nutricionista. Eu acho que a nutrição, ela veio para agregar muitos valores (S2).

Diante de uma formação específica para trabalhar com o alimento e a nutrição, o nutricionista apresenta-se como um profissional apto a atuar na execução e estruturação do PNAE, contribuindo significativamente para a melhoria das condições da merenda escolar e da promoção de hábitos alimentares saudáveis. É preciso buscar, entretanto, a valorização deste profissional no campo da educação e Políticas Públicas, principalmente referentes ao PNAE (SILVA et al., 2018).

\section{CONCLUSÃO}

A percepção de EAN por nutricionistas e secretários de educação demonstrou a importância desta na adoção de hábitos alimentares saudáveis pela comunidade escolar, principalmente pelos alunos. Ao tratar do caráter perceptivo de cada sujeito, a pesquisa buscou atentar para suas perspectivas, seus conceitos, opiniões e experiências ante a EAN. Com base em tais aspectos, os entrevistados destacaram que estas ações de EAN têm caráter fundamental, na medida em que promovem a saúde e a autonomia alimentar, formando atores sociais. A EAN

Editora Unijuí - Revista Contexto \& Saúde - ISSN 2176-7114 - v. 21, n. 43, jul./set. 2021 
também foi identificada como prática reflexiva e contínua. Sobre o que poderia ser feito, os entrevistados destacaram a necessidade de incentivo constante, de projetos integradores, capacitação de professores sobre a temática e, ainda, a importância do trabalho de EAN no ambiente familiar. Conclui-se que a escola se apresenta como ambiente favorável para o desenvolvimento de estratégias de EAN problematizadoras, dialógicas e que considerem a realidade local, fomentando para a necessidade de gestão e adequado planejamento destas ações.

\section{REFERÊNCIAS}

ALMEIDA, Jalcione; NAVARRO, Zander. Reconstruindo a agricultura: ideias e ideais na perspectiva do desenvolvimento rural sustentável. 3. ed. Porto Alegre: Ed. da UFRGS, 2009. p. 33-55.

BARBOSA, Valter Luís; VIDOTTO, Rosângela Cristina; ARRUDA, Tatiane Pascoto. Erosão genética e segurança alimentar. SICI - SIMPÓSIO INTERNACIONAL DE CIÊNCIAS INTEGRADAS. Guarujá, SP: Unaerp, Campus Guarujá, 2015. p. 3.

BOMBARDI, Larissa Mies. Intoxicação e morte por agrotóxicos no Brasil: a nova versão do capitalismo oligopolizado. Bol Dataluta, n. 45, p. 21-1, set. 2011.

BRASIL. Guia alimentar para a população brasileira. 2. ed. Brasília: Ministério da Saúde; Secretaria de Atenção à Saúde; Departamento de Atenção Básica, 2014a. 156 p.

BRASIL. Lei N 11.947, de 16 de julho de 2009. Programa Nacional de Alimentação Escolar. Brasília: Planalto Gov., 2009.

BRASIL. Ministério do Desenvolvimento Social e Combate à Fome. Marco de referência de educação alimentar e nutricional para as políticas públicas. Brasília, DF: MDS; Secretaria Nacional de Segurança Alimentar e Nutricional, 2012.

BRASIL. Lei N 13.666, de 16 de maio de 2018. Altera a Lei no 9.394, de 20 de dezembro de 1996 (Lei de Diretrizes e Bases da Educação Nacional), para incluir o tema transversal da educação alimentar e nutricional no currículo escolar. Brasília: Planalto Gov., 2018b.

BRASIL. Marco de referência de educação popular para as políticas públicas. Brasília, DF: Secretaria Nacional de Articulação Social; Departamento de Educação Popular e Mobilização Cidadã, 2014b. 39 p.

BRASIL. Princípios e práticas para educação alimentar e nutricional. Brasília, DF. 2018a. $50 \mathrm{p}$.

BOOG, Maria Cristina Faber. Educação em nutrição: integrando experiências. Campinas, SP: Komedi, 2013.

D’AVILA, Helen Freitas; CÁS, Samira da; MELLO, Elza Daniel de. Instrumentos para avaliar o comportamento alimentar de crianças e adolescentes. Demetra, Rio de Janeiro, v. 15, p. 1-8. 2020.

DEAL, Barbara et al. Perspective: Childhood Obesity Requires New Strategies for Prevention. Advances in Nutrition, Chicago, v. 1, n. 40, p. 1-9, May. 2020.

FREIRE, Paulo. Educação e mudança. 19. ed. Rio de Janeiro: Paz e Terra, 1983. (Coleção educação e mudança, vol. 19).

FREIRE, Paulo. Pedagogia da autonomia: saberes necessários à prática educativa. 13. ed. Rio de Janeiro: Paz e Terra, 1996.

GOLDUST, Mohamad; ABDELMAKSOUD, Ayman; NAVARINI, Alexander. Hand disinfection in the combat against Covid-19. Journal of the European Academy of Dermatology and Venereology, May. 2020.

LIMA, Romilda de Souza; NETO, José Ambrósio Ferreira; FARIAS, Rita de Cássia Pereira. Alimentação, comida e cultura: o exercício da comensalidade. Demetra, Rio de Janeiro, v. 10, n. 3, p. 507-522, nov. 2015.

LOPES, Wanessa Casteluber et al. Consumo de alimentos ultraprocessados por crianças menores de 24 meses de idade e fatores associados. Revista Paulista de Pediatria, São Paulo, v. 38, p. 8-1, fev. 2020.

Editora Unijuí - Revista Contexto \& Saúde - ISSN 2176-7114 - v. 21, n. 43, jul./set. 2021 
PEREIRA, Janara Portes. Espacialização do uso de agrotóxicos por região de saúde do RS. 2014. 212 f. Monografia (Bacharel em Geografia) - Universidade Federal do Rio Grande do Sul, Instituto de Geociências, Porto Alegre, 2014.

MAGALHÃES, Quitéria Vanessa Brito; CAVALCANTE, Jorge Luís Pereira. Educação alimentar e nutricional como intervenção em hábitos alimentares saudáveis no ambiente escolar. Sanare, Sobral, v. 18. n. 1, p. 59-67, jan./jun. 2019.

MARREIRO, Nicolli Aghape de Melo; ZEMINIAN, Larissa Baungartner. A importância da educação alimentar e nutricional na primeira infância. Revista Medicina e Saúde, Rio Claro, v. 2, n. 3, p. 127-142, jan./jun. 2019.

MEDEIROS, Gidyenne Christine Bandeira Silva de et al. Protocol for systematic reviews of school-based food and nutrition education intervention for adolescent health promotion: Evidence mapping and syntheses. Medicine, Baltimore, v. 98, n. 35, p. 1-6, Aug. 2019.

MODESTO, Adélia Pereira dos Santos; SILVA, Katia Gomes de Oliveira; FUKUI, Regina Kikue. Promoção da ludicidade no processo de aprendizagem. Revista Psicologia \& Saberes, v. 9, n. 14, p. 59-69, 2020.

NASREDDINE, Lara M. et al. Nutritional status and dietary intakes of children amid the nutrition transition: the case of the Eastern Mediterranean Region. Nutrition Research, Beirut, v. 57, p. 12-27, Sept. 2018.

NOGARO, Arnaldo; FINK, Alessandra Tiburski; PITON, Marta Regina Guerra. Brincar: reflexões a partir da neurociência para a consolidação da prática lúdica na educação infantil. Revista HISTEDBR On-line, Campinas, n. 66, p. 278-294, dez. 2015.

RODRIGUES, Jessica Nunes et al. Educação alimentar e nutricional como estratégia para aumento do consumo de proteínas em escolares. Revista Ciências e Ideias, v. 11, n. 1, p. 260-249, abr. 2020.

SILVA, Simoni Urbano da et al. As ações de educação alimentar e nutricional e o nutricionista no âmbito do Programa Nacional de Alimentação Escolar. Ciência e Saúde Coletiva, Rio de Janeiro, v. 23, n. 8, p. 2.671-2.681, ago. 2018.

SOUZA, Luciana Karine de. Pesquisa com análise qualitativa de dados: conhecendo a análise temática. Arquivos Brasileiros de Psicologia, Rio de Janeiro, v. 71, n. 2, p. 51-67, 2019. WILSON, Keren. Obesity: Lifestyle Modification and Behavior Interventions. FP Essentials, v. 492, p. 19-24, May. 2020. 